\title{
PENGARUH BUDAYA SEKOLAH, FASILITAS MENGAJAR, MOTIVASI, DAN KEPUASAN KERJA TERHADAP KINERJA GURU DI SEKOLAH DASAR (SD) NEGERI SE-GUGUS I KECAMATAN STABAT KABUPATEN LANGKAT
}

\author{
Baheramsyah \\ Universitas Islam Sumatera Utara \\ baheramsyah.mm@gmail.com
}

\begin{abstract}
The formulation in this research is whether school culture, teaching facilities, motivation and job satisfaction simultaneously affect the performance of teachers in the elementary School (SD) of cluster state I Se-District Stabat, Langkat District, and the purpose of this research is to know and analyze whether school culture, teaching facilities, motivation and work satisfaction simultaneously affect the performance of teachers in the elementary School (SD) state cluster I Se-District Stabat, Langkat District. This research is a quantitative descriptive study. Data collection techniques are conducted through interviews, questionaire questions and documentation studies. Sample in this study as many as 76 teachers at elementary School (SD) Negeri cluster I Se-District Stabat district of Langkat. Variables are measured at Likert scale. Hypothesis testing using multiple linear regression analyses through F-test and T-Test. The results of the test in unison showed that the variables of the school culture, work facilities and motivation and job satisfaction as a free variable $(X)$ have significant effect on the teachers ' performance variables of the state elementary School cluster I Se-District Stabat District, Langkat. Partially, the school culture has no effect on the state teachers ' performance of cluster I Se-District Stabat, Langkat District. Furthermore, the work facility has a positive and significant effect on the state elementary school teachers cluster I Se-district Stabat in Langkat District. The motivation has positive and significant impact on the state elementary school teachers cluster I Se-district Stabat in Langkat District. Job satisfaction positively and significantly affect the teacher's performance of State Elementary school cluster I Se-District Stabat Langkat District
\end{abstract}

Keyword: school culture, teaching facilities, motivation and job satisfaction of teacher performance

\begin{abstract}
ABSTRAK : Rumusan pada penelitian ini adalah apakah budaya sekolah, fasilitas mengajar, motivasi, dan kepuasan kerja secara simultan berpengaruh terhadap kinerja guru di Sekolah Dasar (SD) Negeri Se-Gugus I Kecamatan Stabat Kabupaten Langkat, dan tujuan penelitian ini adalah untuk mengetahui dan menganalisis apakah budaya sekolah, fasilitas mengajar, motivasi, dan kepuasan kerja secara simultan berpengaruh terhadap kinerja guru di Sekolah Dasar (SD) Negeri Se-Gugus I Kecamatan Stabat Kabupaten Langkat. Penelitian ini merupakan penelitian deskriptif kuantitatif. Teknik pengumpulan data dilakukan melalui wawancara, daftar pertanyaan (questionaire) dan studi dokumentasi. Sampel dalam penelitian ini sebanyak 76 orang Guru di Sekolah Dasar (SD) Negeri SeGugus I Kecamatan Stabat Kabupaten Langkat. Variabel diukur dengan skala Likert. Pengujian hipotesis menggunakan analisis regresi linear berganda melalui uji $F$ dan uji t. Hasil uji secara serempak menunjukkan bahwa Variable Budaya Sekolah, Fasilitas Kerja dan Motivasi, serta Kepuasan Kerja sebagai variabel bebas (X) berpengaruh signifikan terhadap variabel Kinerja Guru SD Negeri Se-Gugus I Kecamatan Stabat Kabupaten Langkat. Secara parsial, budaya sekolah tidak berpengaruh terhadap Kinerja Guru SD Negeri Se-Gugus I Kecamatan Stabat Kabupaten Langkat. Selanjutnya, fasilitas Kerja berpengaruh positif dan signifikan terhadap Kinerja Guru SD Negeri SeGugus I Kecamatan Stabat Kabupaten Langkat. Motivasi berpengaruh positif dan signifikan terhadap Kinerja Guru SD Negeri Se-Gugus I Kecamatan Stabat Kabupaten Langkat. Kepuasan Kerja berpengaruh positif dan signifikan terhadap Kinerja Guru SD Negeri Se-Gugus I Kecamatan Stabat Kabupaten Langkat.
\end{abstract}

Kata kunci : budaya sekolah, fasilitas mengajar, motivasi, kepuasan kerja, kinerja 


\section{Pendahuluan}

Guru sebagai salah satu elemen dari organisasi sekolah diharapkan memiliki kinerja yang tinggi. Sebab dengan kinerja yang tinggi dapat meningkatkan prestasi belajar siswa sehingga dapat memenuhi tujuan sekolah dalam meningkatkan mutu pendidikan. Guru yang memiliki kinerja yang tinggi dapat merasakan nyaman, betah atau membuat guru bertahan di sekolah tempat bekerja. Kinerja yang tinggi dibutuhkan oleh setiap individu dalam mencapai tujuan, baik jangka panjang maupun jangka pendek.

Pada kenyataannya kinerja tinggi tidak semua dimiliki oleh setiap guru, ada juga sebagian guru yang memiliki kinerja rendah. Berdasarkan hasil observasi dan wawancara pada guru yang ada di beberapa sekolah yang mencakup ke dalam Gugus I Kecamatan Stabat Kabupaten Langkat kinerja rendah dapat diketahui melalui orientasi pelayanan atau ketaatan, disiplin, dan kerjasama guru dalam bekerja, seperti halnya masih ada beberapa guru yang terlambat masuk kerja bahkan masuk kelas, kurangnya persiapan ketika bel pergantian pelajaran, bahkan ada guru yang pulang lebih awal dari jam kerja, cara mengajarnya yang masih monoton atau kurang kreatif dalam menyampaikan pelajaran, ketika sedang sakit ada guru yang tidak melimpahkan tugas dan tanggung jawabnya ke guru lainnya, dan guru yang kurang persiapan dalam mengajar serta saat jam kerja terdapat guru yang meninggalkan ruangan untuk berbelanja keperluan rumah tangga, terutama para guru wanita, hal tersebut menyita waktu rata-rata 30 45 menit.

Hal ini mengindikasikan tingkat produktivitas kerja masih rendah, karena hilangnya waktu yang seharusnya dapat digunakan untuk menyelesaikan pekerjaan. Menurut Susanto (2012 : 116) pengendali operasi sekolah adalah kinerja guru, sehingga apabila kinerja guru baik maka kinerja sekolah akan meningkat, sebaliknya kinerja guru menurun maka kinerja sekolah akan mengalami penurunan juga. Oleh karena itu sekolah berusaha untuk menjaga agar tetap memiliki kinerja yang tinggi agar mendapatkan hasil kerja dengan meningkatkan prestasi akademik siswa, sesuai dengan tujuan yang diinginkan sekolah.

Dalam fungsinya sebagai penggerak guru, kepala sekolah harus mampu menciptakan budaya sekolah yang baik dalam menggerakkan guru agar senantiasa mengembangkan kemampuan dan meningkatkan kinerjanya, karena guru merupakan ujung tombak untuk mewujudkan manusia yang berkualitas. Guru akan bekerja secara maksimum apabila didukung oleh beberapa faktor diantaranya adalah kepemimpinan kepala sekolah. Guru merupakan tulang punggung dalam kegiatan pendidikan yang berkaitan dengan kegiatan belajar mengajar. Tanpa adanya peran guru maka proses belajar mengajar akan terganggu bahkan gagal. Oleh karena itu, dalam manajemen pendidikan peranan guru dalam upaya keberhasilan pendidikan selalu ditingkatkan. Kinerja atau prestasi kerja guru harus selalu ditingkatkan untuk menghasilkan kualitas sumber daya manusia yang mampu bersaing di era global.

Mengingat sarana dan prasarana dalam mengajar merupakan salah satu faktor penentu terhadap hasil belajar siswa, maka persyaratan dan penggunaan fasilitas mengajar harus mengacu pada tujuan pembelajaran, metode, penilaian minat siswa dan kemampuan guru. Penggunaan fasilitas mengajar dilakukan secara efekif dan efisien dengan mengacu pada proses belajar mengajar di sekolah.

Seperti telah dijelaskan sebelumnya, peningkatan mutu pendidikan di suatu daerah salah satunya mencakup ketersediaan fasilitas pendidikan terdapat di wilayah tersebut. Fasilitas pendidikan tentu saja berkaitan dengan besarnya jumlah penduduk di wilayah tersebut. Namun demikian, keberadaan fasilitas pendidikan di suatu wilayah belum tentu dapat mengimbangi pertumbuhan penduduk dan jumlah penduduknya yang senantiasa bertambah seiring berjalannya waktu.

Dengan terpenuhinya fasilitas dalam mengajar maka kepuasan guru dalam mengajar dapat terpenuhi pula seperti yang dikemukakan oleh Kreitner dan Angelo (2014 : 146) merumuskan Kepuasan kerja (job satisfaction) adalah sebuah tanggapan afektif atau emosional terhadap berbagai segi pekerjaan seseorang yang mencerminkan tingkatan dimana seseorang menyukai pekerjaannya. Kepuasan kerja guru di sekolah dapat meminimalisir turnover dan tingkat absensi serta diharapkan dapat melejitkan kinerja mereka.

Setiap guru memiliki tingkat kepuasan yang berbeda-beda sesuai dengan nilai yang berlaku pada dirinya. Semakin banyak aspek dalam pekerjaan yang sesuai dengan keinginan diri individu, maka ada kecenderungan semakin tinggi kepuasan kerjanya. Dalam hal ini kepuasan 
kerja pada guru diharapkan dapat meningkatkan kinerja dalam upaya mencapai tujuan organisasi.

Hal ini berkaitan dengan kepuasan guru, yakni harapan guru terhadap kepala sekolah dengan kenyataan yang diberikan olehnya. Jika harapan guru sesuai dengan imbalan yang diberikan oleh kepala sekolah kemungkinan bisa membuat puas guru. Imbalan di sini bukan hanya segi materil seperti kenaikan gaji, tunjangan, atau honor tapi juga spiritual seperti perhatian kepala sekolah, komunikasi yang baik antar guru dengan kepala sekolah, dan dorongan/motivasi oleh kepala sekolah.

Motivasi merupakan daya dorong seseorang untuk melakukan kegiatan tertentu. Guru menjadi seorang pendidik karena adanya motivasi untuk mendidik. Jika tidak punya motivasi maka ia tidak berhasil untuk mendidik/mengajar atau dia mengajar karena terpaksa saja. Keberhasilan guru dalam mengajar karena dorongan/motivasi ini sebagai pertanda apa yang dilakukan oleh guru itu telah menyentuh kebutuhannya. Kegiatan mengajar dilakukan oleh guru yang diminatinya karena sesuai dengan kebutuhannya, jika orang lain tidak minat menjadi guru, hal itu disebabkan karena kebutuhan tidak sesuai dengan kepentingannya sendiri. Guru yang termotivasi dalam bekerja maka akan menimbulkan kepuasan kerja, karena kebutuhan-kebutuhan guru yang terpenuhi mendorong guru meningkatkan kinerjanya.

\subsection{Rumusan Masalah}

Berdasarkan uraian diatas, maka masalah dalam penelitian ini dirumuskan sebagai berikut : bagaimana pengaruh budaya sekolah, fasilitas mengajar, motivasi, dan kepuasan kerja berpengaruh terhadap kinerja guru di Sekolah Dasar (SD) Negeri Se-Gugus I Kecamatan Stabat Kabupaten Langkat.

\subsection{Batasan Masalah}

Agar lebih memfokuskan arah penelitian ini kepada penulisan, maka pembatasan masalah sangat diperlukan. Pembatasan masalah dilakukan karena keterbatasan waktu, biaya, peralatan, dan kendala lainnya sehingga memungkinkan tercapainya tujuan penelitian.

Tabel 1 Kerangka Populasi Berdasarkan Status Guru TP. 2019/2020

\begin{tabular}{|c|l|c|c|c|}
\hline \multirow{2}{*}{ No } & Jabatan & \multicolumn{2}{|c|}{ Status Guru } & \multirow{2}{*}{ Jumlah } \\
\cline { 3 - 4 } & & PNS & $\begin{array}{c}\text { Non } \\
\text { PNS }\end{array}$ & \\
\hline 1 & SDN 050656 Stabat & 14 & 7 & 21 \\
\hline 2 & SDN 050659 Stabat & 16 & 2 & 18 \\
\hline
\end{tabular}

Penelitian ini difokuskan pada lima variabel penelitian, yaitu budaya sekolah, fasilitas mengajar, motivasi, kepuasan kerja dan kinerja guru di Sekolah Dasar ( SD ) Negeri Se-Gugus I Kecamatan Stabat Kabupaten Langkat.

\subsection{Hipotesis}

Hipotesa merupakan jawaban sementara atau dugaan sementara permasalahan sebelum melakukan penelitian yang sesungguhnya dilapangan. Dengan jawaban sementara penelitian dapat lebih diarahkan pada pokok permasalahan. Jadi hipotesis dalam penelitian ini adalah sebagai berikut, adanya pengaruh siginifikan antara Budaya sekolah, fasilitas mengajar, motivasi, dan kepuasan kerja terhadap kinerja guru di Sekolah Dasar (SD) Negeri SeGugus I Kecamatan Stabat Kabupaten Langkat.

\subsection{Tujuan Penelitian}

a. Untuk mengetahui pengaruh budaya sekolah terhadap kinerja guru di Sekolah Dasar (SD) Negeri Se-Gugus I Kecamatan Stabat Kabupaten Langkat.

b. Untuk mengetahui pengaruh fasilitas mengajar terhadap kinerja guru di Sekolah Dasar (SD) Negeri Se-Gugus I Kecamatan Stabat Kabupaten Langkat .

c. Untuk mengetahui pengaruh motivasi terhadap kinerja guru di Sekolah Dasar (SD) Negeri Se-Gugus I Kecamatan Stabat Kabupaten Langkat.

d. Untuk mengetahui pengaruh kepuasan kerja terhadap kinerja guru di Sekolah Dasar (SD) Negeri Se-Gugus I Kecamatan Stabat Kabupaten Langkat.

e. Untuk mengetahui pengaruh budaya sekolah, fasilitas mengajar, motivasi dan kepuasan kerja secara simultan terhadap kinerja guru di Sekolah Dasar (SD) Negeri Se-Gugus I Kecamatan Stabat Kabupaten Langkat.

\section{Metode Penelitian}

\subsection{Populasi dan Sampel}

Populasi dalam penelitian ini adalah guru SD Negeri Se-Gugus I Kecamatan Stabat Kabupaten Langkat sebanyak 114 orang. 


\begin{tabular}{|c|l|c|c|c|}
\hline \multirow{2}{*}{ No } & \multirow{2}{*}{ Jabatan } & \multicolumn{2}{|c|}{ Status Guru } & \multirow{2}{*}{ Jumlah } \\
\cline { 3 - 4 } & & PNS & $\begin{array}{c}\text { Non } \\
\text { PNS }\end{array}$ & \\
\hline 3 & SDN 050666 Lubuk Dalam & 10 & 10 & 20 \\
\hline 4 & SDN 050667 Lubuk Dalam & 6 & 4 & 10 \\
\hline 5 & SDN 053974 Paya Mabar & 9 & 2 & 11 \\
\hline 6 & SDN 054907 Gang Sentosa & 7 & 4 & 11 \\
\hline 7 & SDN 056615 Wonosari & 8 & 3 & 11 \\
\hline 8 & SDN 057203 Ara Condong & 6 & 6 & 12 \\
\hline \multicolumn{2}{|c|}{ Jumlah } & $\mathbf{7 6}$ & $\mathbf{3 8}$ & $\mathbf{1 1 4}$ \\
\hline
\end{tabular}

Sumber: Dinas Pendidikan (KKG) Gugus I Kecamatan Stabat Kabupaten Langkat

Dalam penelitian ini penulis menggunakan teknik Purposive Random Sampling, yaitu teknik penentuan sampel dengan pertimbangan tertentu artinya setiap subjek yang diambil dari populasi dipilih dengan sengaja berdasarkan tujuan dan pertimbangan tertentu (Sugiyono, 2010:131). Kriteria penentuan sampel didasarkan pada subjek yang aktif dalam mengikuti kegiatan KKG

Tabel 2. Kerangka Sampel Berdasarkan Status Guru TP. 2019/2020

\begin{tabular}{|c|c|c|c|}
\hline No & Jabatan & Jlh Sampel & Ket \\
\hline 1 & SDN 050656 Stabat & 14 & Diteliti \\
\hline 2 & SDN 050659 Stabat & 16 & Diteliti \\
\hline 3 & SDN 050666 Lubuk Dalam & 10 & Diteliti \\
\hline 4 & SDN 050667 Lubuk Dalam & 6 & Diteliti \\
\hline 5 & SDN 053974 Paya Ambar & 9 & Diteliti \\
\hline 6 & SDN 054907 Gang Sentosa & 7 & Diteliti \\
\hline 7 & SDN 056615 Wonosari & 8 & Diteliti \\
\hline 8 & SDN 057203 Ara Condong & 6 & Diteliti \\
\hline \multicolumn{2}{|r|}{ Jumlah } & 76 & \\
\hline
\end{tabular}

\subsection{Uji Normalitas Data}

Uji normalitas adalah untuk melihat apakah nilai residual terdistribusi normal atau tidak. Model regresi yang baik adalah memiliki nilai residual yang terdistribusi normal. Jadi uji normalitas bukan dilakukan pada masing-masing variabel tetapi pada nilai residualnya. Sering terjadi kesalahan yang jamak yaitu bahwa uji normalitas dilakukan pada masing-masing variabel. Hal ini tidak dilarang tetapi model regresi memerlukan normalitas pada nilai residualnya bukan pada masing-masing variabel penelitian. Pengujian normalitas data penelitian adalah untuk menguji apakah dalam model statistik variabel-variabel penelitian berdistribusi normal atau tidak normal. Model regresi yang tinggi adalah memiliki distribusi normal atau mendekati normal. Untuk menguji apakah distribusi data normal atau tidak, salah satunya dengan menggunakan metode gambar normal Probabilitas Plots digunakan untuk pada Gugus I Kecamatan Stabat Kabupaten Langkat dan dianggap dapat mewakili subjek yang tidak dijadikan populasi dalam penelitian ini. Aktifitas guru dalam mengikuti kegiatan KKG pada Gugus I Kecamatan Stabat Kabupaten Langkat dibuktikan dengan absensi kehadiran guru. menyimpulkan apakah model analisis memenuhi asumsi normal, dengan penyebaran data di sekitar garis diagonal dan mengikuti arah garis diagonal maka data tersebut mememenuhi asumsi normal dalam model analisis, yang dapat dilihat pada gambar dibawah ini :

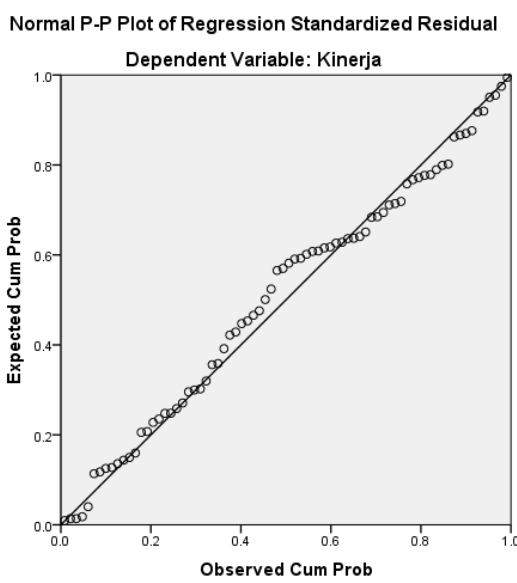

Gambar 1. Hasil Pengujian Normalitas -Diagonal 
Berdasarkan gambar 1 di atas, terlihat bahwa distribusi dari titik-titik data Budaya Sekolah, Fasilitas Mengajar, Motivasi, dan Kepuasan Kerja serta Kinerja Guru menyebar. Grafik P-P Plot di atas menunjukan bahwa sebaran data menyebar di sekitar garis diagonal, sehingga asumsi normalitas dipenuhi. Maka model regresi layak dipakai untuk memprediksi Kinerja berdasarkan variabel independennya.

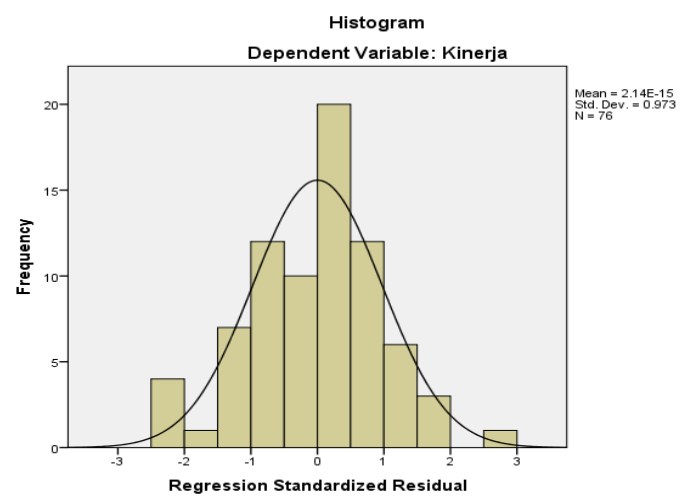

Gambar 2. Hasil Pengujian NormalitasHistogram

Berdasarkan gambar 2, diatas terlihat bahwa grafik histogram memberikan pola distribusi normal tidak berpola distribusi melenceng (skweness) ke kiri atau ke kanan, maka model regresi memenuhi asumsi normalitas.

\subsection{Uji Multikolinearitas}

Multikolinieritas berati adanya hubungan yang kuat diantara beberapa atau semua variabel bebas pada model regresi. Jika terdapat multikolinieritas maka koefisien regresi menjadi tidak tentu, tingkat kesalahannya menjadi sangat besar dan biasanya ditandai dengan koefisien determinasi yang sangat besar tetapi pada pengujian parsial koefisien regresi, tidak ada atau pun kalau ada sangat sedikit sekali koefisien regresi yang signifikan. Pada penelitian ini digunakan nilai Variance Inflantion Factorrs (VIF) sebagai indikator ada tidaknya multikolinearitas di antara variabel bebas.

Tabel 3. Uji Multikolinieritas Coefficients $^{\mathrm{a}}$

\begin{tabular}{|c|c|c|c|}
\hline \multirow{2}{*}{\multicolumn{2}{|c|}{ Model }} & \multicolumn{2}{|c|}{ Collinearity Statistics } \\
\hline & & Tolerance & VIF \\
\hline \multirow{5}{*}{1} & (Constant) & & \\
\hline & Budaya_Sekolah & .885 & 1.131 \\
\hline & Fasilitas_Mengajar & .919 & 1.088 \\
\hline & Motivasi & .930 & 1.075 \\
\hline & Kepuasan & .871 & 1.148 \\
\hline
\end{tabular}

Berdasarkan output tabel 3, hasil perhitungan nilai variance inflaction factor (VIF) juga menunjukkan bahwa tidak ada satu variabel independen yang memiliki nilai VIF lebih dari 10. Jadi dapat disimpulkan bahwa tidak ada multikolinieritas antar variabel independen dalam model regresi.

\subsection{Uji Heteroskedastisitas}

Uji heteroskedastisitas dilakukan untuk mengetahui apakah dalam sebuah model regresi terjadi ketidaksamaan varians dari residual suatu pengamatan ke pengamatan lain. Jika varians dari residual suatu pengamatan ke pengamatan lain tetap disebut heteroskedastisitas.

Menganalisis data dalam pengujian asumsi klasik ini, peneliti menggunakan Program Statistical Product and Service Solution (SPSS Versi 20.) for Windows dapat dilihat pada gambar 3 berikut ini :

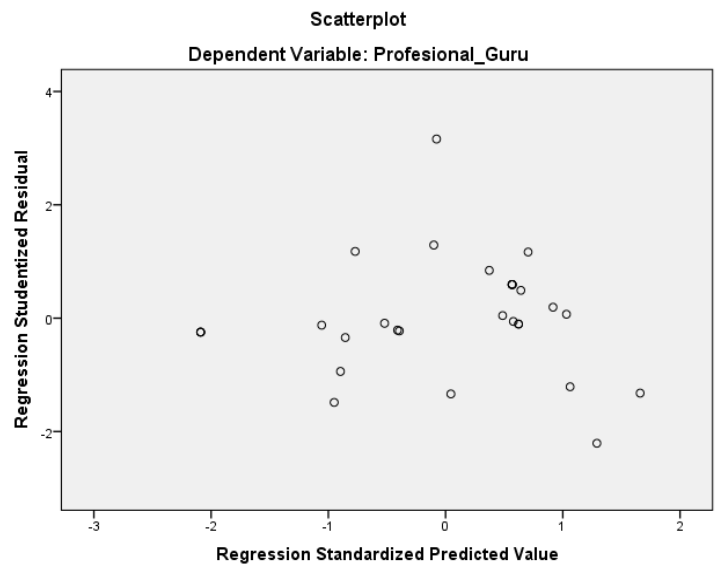

Gambar 3 Grafik scatterplot Uji Heteroskedastisitas

Dari gambar di atas menunjukkan bahwa diagram pencar tidak membentuk suatu pola atau acak, dengan demikian dapat dikatakan bahwa regresi tidak mengalami gangguan heteroskedastisitas pada model regresi sehingga model regresi layak dipakai untuk mengetahui Kinerja Guru (Y) berdasarkan variabel bebasnya.

\section{Hasil dan Pembahasan}

\subsection{Analisis Regresi Linier Berganda}

Analisis regresi linier berganda digunakan untuk mengetahui berapa besar Pengaruh Budaya Sekolah, Fasilitas Mengajar dan Motivasi serta Kepuasan Kerja Terhadap Kinerja Guru SD Negeri Se-Gugus I Kecamatan Stabat Kabupaten Langkat. Analisis dilakukan dengan 
menggunakan bantuan SPSS versi 20 dengan output sebagai berikut:

Tabel 4. Regresi Linear Berganda

Coefficients $^{\mathrm{a}}$

\begin{tabular}{|c|c|c|c|c|c|c|}
\hline \multirow[t]{2}{*}{ Mo } & & \multicolumn{2}{|c|}{ Unstandardized Coefficients } & \multirow{2}{*}{$\begin{array}{c}\text { Standardized } \\
\text { Coefficients } \\
\text { Beta }\end{array}$} & \multirow[t]{2}{*}{$\mathrm{t}$} & \multirow[t]{2}{*}{ Sig. } \\
\hline & & $\mathrm{B}$ & Std. Error & & & \\
\hline \multirow{5}{*}{1} & (Constant) & 13.817 & 5.128 & & 2.694 & .009 \\
\hline & Budaya_Sekolah & .008 & .036 & .023 & .220 & .826 \\
\hline & Fasilitas_Mengajar & .177 & .071 & .254 & 2.501 & .015 \\
\hline & Motivasi & .337 & .086 & 399 & 3.940 & .000 \\
\hline & Kepuasan & 297 & .095 & 327 & 3.127 & .003 \\
\hline
\end{tabular}

Berdasarkan pengolahan data yang terlihat pada tabel 4, output kolom kedua bagian B (Unstandardized Coefficients), diperoleh persamaan regresi linier berganda yaitu:

$$
\begin{aligned}
& y=a+b_{1} x_{1}+b_{2} x_{2}+b_{3} x_{3}+\varepsilon \\
& Y=13.817+0.008 X_{1}+0.177 X_{2}+0.337 X_{3}+ \\
& 0.297 \mathrm{X}_{4}+\varepsilon
\end{aligned}
$$

Dengan persamaan regresi linier berganda tersebut dapat dijelaskan bahwa:

a. Nilai konstanta adalah sebesar 13.817 hal ini menyatakan bahwa jika variable Pendidikan, Fasilitas Mengajar, dan Motivasi diabaikan, maka nilai Kinerja Guru sebesar 13.817.

b. Koefisien regresi untuk variabel Budaya Sekolah sebesar 0.008 hal ini menunjukkan bahwa setiap kenaikan $1 \%$ faktor Budaya Sekolah maka akan meningkatkan Kinerja Guru sebesar $0.8 \%$.

c. Koefisien regresi untuk variabel Fasilitas Mengajar sebesar 0.177 hal ini menunjukkan bahwa setiap kenaikan $1 \%$ faktor Fasilitas Mengajar maka akan meningkatkan Kinerja Guru sebesar $17.7 \%$.

d. Koefisien regresi untuk variabel Motivasi sebesar 0,337 hal ini menunjukkan bahwa setiap kenaikan $1 \%$ faktor Motivasi maka akan meningkatkan Kinerja Guru sebesar $33.7 \%$.

e. Koefisien regresi untuk variabel Kepuasan Kerja sebesar 0,297 hal ini menunjukkan bahwa setiap kenaikan $1 \%$ faktor Kepuasan Kerja maka akan meningkatkan Kinerja Guru sebesar $29.7 \%$.

\subsection{Hipotesis}

\subsubsection{Uji Simultan ( Uji- f )}

Pengaruh Budaya Sekolah, Fasilitas Mengajar, dan Motivasi serta Kepuasan kerja sebagai variabel bebas (X) terhadap Kinerja Guru sebagai variabel terikat (Y) Di SD Negeri SeGugus I Kecamatan Stabat Kabupaten Langkat dapat dilihat pada Tabel 5 berikut.

Tabel 5. Hasil Uji Serempak

ANOVA $^{\text {a }}$

\begin{tabular}{|rl|r|r|r|r|r|}
\hline \multicolumn{1}{|l|}{ Model } & \multicolumn{1}{c|}{$\begin{array}{c}\text { Sum of } \\
\text { Squares }\end{array}$} & df & Mean Square & F & Sig. \\
\hline \multirow{2}{*}{1} & Regression & 199.642 & 4 & 49.910 & 8.512 & $.000^{\mathrm{b}}$ \\
& Residual & 416.306 & 71 & 5.863 & & \\
\cline { 2 - 6 } & 615.947 & 75 & & & \\
\hline
\end{tabular}

a. Dependent Variable: Kinerja

b. Predictors: (Constant), Kepuasan, Motivasi, Fasilitas_Mengajar, Budaya_Sekolah

Pada Tabel 5 di atas terlihat nilai signifikansi sebesar $0.000^{\mathrm{b}}$ lebih kecil dari $\alpha=0,05$, hal ini berarti bahwa variabel Budaya Sekolah, Fasilitas Mengajar, dan Motivasi serta Kepuasan Kerja sebagai variabel bebas memiliki pengaruh yang highly significant. Secara serempak variabel Budaya Sekolah, Fasilitas Mengajar, dan Motivasi serta Kepuasan Kerja menunjukkan pengaruh sangat nyata terhadap Kinerja Guru SD Negeri Se Gugus I -Kecamatan Stabat Kabupaten Langkat .

\subsubsection{Uji Parsial ( Uji- t )}

Uji pengaruh variabel Budaya Sekolah, Fasilitas Mengajar, dan Motivasi serta Kepuasan 
Kerja secara parsial dapat dilihat pada Tabel 6 berikut ;

Tabel 6. Hasil Uji Parsial

Coefficients $^{\mathbf{a}}$

\begin{tabular}{|c|c|c|c|c|c|c|}
\hline \multicolumn{2}{|c|}{ Model } & \multicolumn{2}{|c|}{ Unstandardized Coefficients } & \multirow{2}{*}{$\begin{array}{c}\text { Standardized } \\
\text { Coefficients }\end{array}$} & \multirow[t]{2}{*}{$\mathrm{t}$} & \multirow[t]{2}{*}{ Sig. } \\
\hline & & B & Std. Error & & & \\
\hline \multirow{5}{*}{1} & (Constant) & 13.817 & 5.128 & & 2.694 & .009 \\
\hline & Budaya_Sekolah & .008 & .036 & .023 & .220 & .826 \\
\hline & Fasilitas_Mengajar & .177 & .071 & .254 & 2.501 & .015 \\
\hline & Motivasi & .337 & .086 & .399 & 3.940 & .000 \\
\hline & Kepuasan & 297 & .095 & .327 & 3.127 & .003 \\
\hline
\end{tabular}

a. Dependent Variable: Profesional_Guru

Dari Tabel 6, diperoleh nilai $t_{\text {hitung }}$ masingmasing variabel. Nilai $t_{\text {hitung }}$ tersebut selanjutnya dibandingkan dengan nilai $t_{\text {tabel }}$ pada tingkat kepercayaan $95 \%$ atau $\alpha=0,05$. Nilai $t_{\text {tabel }}$ pada df 4:76 dengan $\alpha=0,05$ adalah 1.992. Pengaruh parsial dari variabel Budaya Sekolah $\left(\mathrm{X}_{1}\right)$ diperoleh dengan nilai $t_{\text {hitung }}$ sebesar 0.220 , dengan demikian $t_{\text {hitung }}<t_{\text {tabel }}(0.220<1.992)$ dengan nilai signifikan sebesar $0.826>0.05$, maka $\mathrm{H}_{0}$ diterima dan $\mathrm{H}_{1}$ ditolak, yang berarti bahwa variabel Budaya Sekolah $\left(\mathrm{X}_{1}\right)$ tidak berpengaruh terhadap Kinerja Guru SD Negeri Se-Gugus I Kecamatan Stabat Kabupaten Langkat.

Pengaruh parsial dari variabel Fasilitas Mengajar $\left(\mathrm{X}_{2}\right)$ diperoleh dengan nilai $\mathrm{t}_{\text {hitung }}$ sebesar 2.501, dengan demikian $t_{\text {hitung }}>t_{\text {tabel }}$ $(2.501>1.992)$ dengan nilai signifikan sebesar $0.015<0.05$, maka $\mathrm{H}_{0}$ ditolak dan $\mathrm{H}_{1}$ diterima, yang berarti bahwa variabel Fasilitas Mengajar $\left(\mathrm{X}_{2}\right)$ berpengaruh positif dan signifikan terhadap Kinerja Guru SD Negeri Se-Gugus I Kecamatan Stabat Kabupaten Langkat . Hal ini berarti bahwa apabila Fasilitas Mengajar $\left(\mathrm{X}_{2}\right)$ meningkat atau semakin baik maka Kinerja Guru SD Negeri SeGugus I Kecamatan Stabat Kabupaten Langkat juga akan meningkat.

Pengaruh parsial dari variabel Motivasi $\left(\mathrm{X}_{3}\right)$ diperoleh dengan nilai $t_{\text {hitung }}$ sebesar 3.940, dengan demikian $t_{\text {hitung }}>t_{\text {tabel }}(3.940>1.992)$ dengan nilai signifikan sebesar $0.000<0.05$, maka $\mathrm{H}_{0}$ ditolak dan $\mathrm{H}_{1}$ diterima, yang berarti bahwa variabel Motivasi $\left(\mathrm{X}_{3}\right)$ berpengaruh positif dan signifikan terhadap Kinerja Guru SD Negeri Se-Gugus I Kecamatan Stabat Kabupaten Langkat. Hal ini berarti bahwa apabila Motivasi $\left(\mathrm{X}_{3}\right)$ meningkat atau semakin baik maka Kinerja Guru SD Negeri Se-Gugus I Kecamatan Stabat Kabupaten Langkat juga akan meningkat.

Pengaruh parsial dari variabel Kepuasan Kerja $\left(\mathrm{X}_{4}\right)$ diperoleh dengan nilai $\mathrm{t}_{\text {hitung }}$ sebesar 3.127, dengan demikian $t_{\text {hitung }}>t_{\text {tabel }}(3.127>1.992)$ dengan nilai signifikan sebesar $0.003<0.05$, maka $\mathrm{H}_{0}$ ditolak dan $\mathrm{H}_{1}$ diterima, yang berarti bahwa variabel Kepuasan Kerja $\left(\mathrm{X}_{4}\right)$ berpengaruh positif dan signifikan terhadap Kinerja Guru SD Negeri Se-Gugus I Kecamatan Stabat Kabupaten Langkat. Hal ini berarti bahwa apabila Kepuasan kerja $\left(\mathrm{X}_{4}\right)$ meningkat atau semakin baik maka Kinerja Guru SD Negeri Se-Gugus I Kecamatan Stabat Kabupaten Langkat juga akan meningkat.

Berdasarkan hasil analisis diketahui bahwa nilai koefisien regresi yang paling tinggi adalah variabel Motivasi Kerja Guru $\left(\mathrm{X}_{3}\right)$ sebesar 0.399 atau $39.9 \%$. Hal ini berarti bahwa Motivasi Kerja Guru $\left(\mathrm{X}_{3}\right)$ berpengaruh lebih dominan terhadap Kinerja Guru SD Negeri Se-Gugus I Kecamatan Stabat Kabupaten Langkat .

\subsubsection{Uji Determinasi $\boldsymbol{R}^{2}$}

Tabel 7. Koefisien Determinasi

Model Summary ${ }^{b}$

\begin{tabular}{|c|c|c|c|c|c|c|c|}
\hline \multirow[t]{2}{*}{ Model } & \multirow[t]{2}{*}{$\mathrm{R}$} & \multirow[t]{2}{*}{ R Square } & \multirow{2}{*}{$\begin{array}{l}\text { Adjusted R } \\
\text { Square }\end{array}$} & \multirow{2}{*}{$\begin{array}{l}\text { Std. Error of } \\
\text { the Estimate }\end{array}$} & \multicolumn{3}{|c|}{ Change Statistics } \\
\hline & & & & & $\begin{array}{l}\text { R Square } \\
\text { Change }\end{array}$ & F Change & df1 \\
\hline 1 & $.569^{\mathrm{a}}$ & .324 & .286 & 2.421 & .324 & 8.512 & 4 \\
\hline
\end{tabular}

a. Predictors: (Constant), Kepuasan, Motivasi, Fasilitas_Mengajar, Budaya_Sekolah

b. Dependent Variable: Kinerja 
Nilai koefisien determinasi sebesar 0,324 berarti bahwa Kinerja Guru SD Negeri Se-Gugus I Kecamatan Stabat Kabupaten Langkat dapat dijelaskan oleh perubahan Budaya Sekolah, Fasilitas Mengajar, dan Motivasi serta Kepuasan Kerja sebesar $32.4 \%$, sedangkan sisanya sebesar $67.6 \%$ dipengaruhi oleh variable lain yang tidak dianalisis dalam penelitian ini.

\section{Kesimpulan}

Berdasarkan uraian dan penjelasan dari babbab yang terdahulu, maka penulis mengambil kesimpulan sebagai berikut:

a. Variabel Budaya Sekolah $\left(\mathrm{X}_{1}\right)$ tidak berpengaruh terhadap Kinerja Guru SD Negeri Se-Gugus I Kecamatan Stabat Kabupaten Langkat.

b. Variabel Fasilitas Kerja $\left(\mathrm{X}_{2}\right)$ berpengaruh positif dan signifikan terhadap Kinerja Guru SD Negeri Se-Gugus I Kecamatan Stabat Kabupaten Langkat.

c. Variabel Motivasi $\left(\mathrm{X}_{3}\right)$ berpengaruh positif dan signifikan terhadap Kinerja Guru SD Negeri Se-Gugus I Kecamatan Stabat Kabupaten Langkat.

d. Variabel Kepuasan Kerja $\left(\mathrm{X}_{4}\right)$ berpengaruh positif dan signifikan terhadap Kinerja Guru SD Negeri Se-Gugus I Kecamatan Stabat Kabupaten Langkat

e. Variable Budaya Sekolah, Fasilitas Kerja, dan Motivasi serta Kepuasan Kerja sebagai variabel bebas $(\mathrm{X})$ berpengaruh signifikan terhadap variabel Kinerja Guru SD Negeri SeGugus I Kecamatan Stabat Kabupaten Langkat

f. Nilai koefisien regresi yang paling tinggi adalah variabel Motivasi Kerja Guru $\left(\mathrm{X}_{3}\right)$ sebesar 0.399 atau $39.9 \%$ yang berarti bahwa memiliki pengaruh lebih dominan terhadap Kinerja Guru SD Negeri Se-Gugus I Kecamatan Stabat Kabupaten Langkat .

\section{DAFTAR PUSTAKA}

Arifin, Zainal. 2012. Penelitian Pendidikan Metode dan Paradigma Baru. Bandung : Remaja Rosda Karya.

Arikunto, Suharsimi. 2011. Prosedur Penelitian Suatu Pendekatan Praktek. Jakarta : PT. Rineka Cipta.

As'ad, Mohammad. 2013. Seri Ilmu Sumber Daya Manusia: Psikologi Industri, Edisi IV. Yogyakarta : Liberty.

Bafadal, Ibrahim. 2010. Manajemen Perlengkapan Sekolah Teori dan Aplikasinya. Jakarta : Bumi Aksara.
Barnawi dan Arifin. 2012. Etika dan Profesi Kependidikan. Jogjakarta : Ar-Ruzz Media.

Barnawi. 2013. Kinerja Guru Profesional. Jogjakarta : Ar-Ruzz Media.

Brophy, J. 2014. Motivating Students to Learning. New Jersey : Lawrence Erlbaum Associates.

Daryanto. 2011. Media Pembelajaran. Bandung : PT. Sarana Tutorial Nurani Sejahtera.

Depdikbud. 2004 Tentang Standard Kompetensi Pendidikan. Jakarta : Puskur.Dit. PTKSD.

Ghozali, Mohammad. 2013. Pengaruh Tingkat Kedisiplinan Kerja dan Budaya Organisasi Terhadap Kinerja Pegawai Pada Kantor Kementrian Agama Kab. Pasuruan. Jurnak e-book.

Djamarah, Syaiful Bahri. 2012. Strategi Belajar Mengajar. Jakarta : Rineka Cipta.

Djoyowirono. 2015. Manajemen Suatu Paradigma. Edisi keempat. Yogyakarta : BPFE.

Gunarsa. S. 2016. Psikologi Manajemen Pendidikan. Jakarta : Gunung Mulia.

Hamzah, B. 2011. Belajar Dengan Pendekatan PAILKEM. Jakarta : Bumi Aksara.

Hamzah, Uno. 2015. Teori Motivasi \& Pengukurannya : Analisis di Bidang Pendidikan. Jakarta : Bumi Aksara.

Hartanto. Amin Nur. 2015. Nilai-Nilai Manajemen Pendidikan. Bandung : Alfabeta.

Husnan, Saud. 2011. Dasar-Dasar Manajemen. Yogyakarta : UPP STTIM YKPN.

Harvey, D. Dan Bown D. R. 2016. An Experimental Approach to Organizational Development. New Jersey : Pearson Prentice Hall.

Ibnu Kholiq Masruri, Ghufron Abdullah dan Ngasbun Egar. 2017. Pengaruh Budaya Organisasi Sekolah dan Motivasi Kerja Guru Terhadap Kinerja Guru Sekolah Dasar di Kecamatan Petarukan Kabupaten Pemalang. Jurnal.

Juwita, Marni. 2016. Pengaruh Budaya Organisasi, Komitmen Guru Dan Motivasi Terhadap Kinerja Guru SMP Negeri 03 Mukomuko. Tesis : Tidak Diterbitkan.

Kotler, Philip dan Kevin, Lane Keller. 2015. Manajemen Pemasaran : Edisi I Jilid 2. Jakarta : Pt. Indeks.

Kreitner, Robert and Angelo Kinichi. 2014. Organizational Behavior. Fifth Edition. Irwin McGraw-Hill. 
Lupiyaodi, Rambat. 2016. Manajemen Pemasaran Jasa. Jakarta : Salemba Empat.

Luthans, Fred. 2016. Organizational Behavior; An Evidence-Based Approach, 13th Ed, Alih Bahasa Vivi Andika Yuwono dkk, Andi, Yogyakarta.

Mangkunegara. 2015. Manajemen Sumber Daya Manusia Perusahaan. Bandung : Remaja Rosdakarya

Mulyasa, E. 2011. Manajemen Berbasis Sekolah. Bandung : PT. Remaja Rosda Karya.

Munandar, M. 2016. Budgeting Perencanaan Kerja Pengkoordinasian Kerja Pengawasan Kerja. Yogyakarta : BPFEE.

Printrich, P.R. 2013. Motivation and Classroom Learning. New Jersey : JohnWiley \& Son Inc.

Priyanti, Endah Tri. 2016. Tehnik Pemberdayaan Guru. Jakarta : Bumi Aksara.

Robbins, Stephen P. 2013. The Principle of Organizational Behaviour. USA: Prentice Hall Inn.

Robbins, Stephen P. 2016. Perilaku Organisasi. Edisi Revisi. Jakarta : Gramedia.

Santrock, J.W. 2007. Psikologi Pendidikan Edisi Kedua. Jakarta : Prenada Media Group.

Sardiman, A.M. 2010. Interaksi dan Motivasi Belajar Mengajar. Jakarta : Raja Grafindo Persada.

Sardiman, A.M. 2017. Kepemimpinan dan Motivasi. Jakarta : Raja Grafindo Persada.

Sathe, Vijay. 2016. Culture and Related Coorporate Realities. Home Wild : RichardD. Irwin.Inc.

Schein, Edgar H. 2014. Organizational Culture and Leadership Third Edition. San Fransisco : Jossey - Bas.

Schein, Edgar H. 2016. Organizational Culture. San Fransisco : Jossey - Bas.

Siagian, Sondang P. 2013. Manajemen Sumber Daya Manusia. Jakarta : Bumi Aksara.

Siswanto, Bejo. 2016. Manajemen Tenaga Kerja Indonesia Pendekatan Administratif dan Operasional. Jakarta : Bumi Aksara.

Sobirin, Ahmad. 2013. Pengaruh Budaya Organisasi Dan Motivasi Kerja Terhadap Kinerja Guru Di SMP Islamiyah Ciputat Tangerang. Jurnal.

Sugiyono. 2010. Metode Penelitian Bisnis Cetakan kesembilan. Bandung: Alfabeta.
Sugiyono. 2014. Metode Penelitian Pendidikan Pendekatan Kuantitatif, Kualitatif dan R\&D. Bandung : Alfabeta.

Suharsimi, Arikunto. 2016. Prosedur Penelitian : Suatu Pendekatan Praktek (Edisi Revisi). Jakarta : Rineka Cipta.

Sumodiningrat, Gunawan. 2001. Manajemen Pendidikan. Yogyakarta : Pustaka Pelajar.

Supardi. 2013. Aplikasi Statistika dalam Penelitian Konsep Statistika yang Lebih Komperhensif. Jakarta : Change Publication.

Supardi. 2014. Kinerja Guru. Jakarta : PT. Raja Grafindo Persada.

Suparlan. 2010. Manajemen Sumber Daya Manusia. Yogyakarta : YKPN.

Suryabrata. 2017. Metode Penelitian. Jakarta : Rajawali Press.

Suryosubroto. 2016. Proses Belajar Mengajar di Sekolah. Jakarta : Rineka Cipta.

Susanto, Singgih. 2012. Panduan Lengkap SPSS Versi 20. Jakarta : Elex Media Kompetindo.

Tika, Pabundu. 2016. Budaya Organisasi dan Peningkatan Kinerja Karyawan. Jakarta : Bumi Aksara.

Umar, Husein. 2010. Riset Pemasaran dan Perilaku Konsumen. Jakarta : Pt. Gramedia Pustaka Utama.

Walgito, Bimo. 2013. Pengantar Psikologi Umum. Yogyakarta : ANDI.

Yoshinta, Anis. 2018. Pengaruh Kepuasan Kerja, Motivasi, dan Fasilitas Mengajar Terhadap Kinerja Guru di MTs Negeri 1 Bandar Lampung. Tesis : Tidak Diterbitkan. Zamroni. 2013. Paradigma Pendidikan Masa Depan. Yogyakarta : Bigraf Publishing. 